\title{
Nidamental Gland Mucosubstance from the Squid Illex argentinus: Salt-soluble Component as a Mucin Complex
}

\author{
Yoko Sugiura and Shigeru Kimura ${ }^{\dagger}$ \\ Laboratory of Food Chemistry, Tokyo Uuiversity of Fisheries, Minato, Tokyo 108, Japan \\ (Received March 30, 1995)
}

\begin{abstract}
Spawned eggs of the squid Illex argentinus are assumed to be wrapped up in fragile gels which are largely derived from the mucosubstance of nidamental glands. This mucosubstance is known to contain mucin-type glycoprotein as a main constituent. In this study, the soluble components of mucosubstance were prepared by sequential extraction with deionized water and $0.6 \mathrm{M} \mathrm{NaCl}, \mathrm{pH} \mathrm{7.2}$. The water-soluble component was poor in amino sugars and exhibited a low viscosity in solution, indicating the virtual absence of mucin. On the other hand, the salt-soluble component was relatively rich in amino sugars and had a high intrinsic viscosity of $10.0 \mathrm{~d} l / \mathrm{g}$. Moreover, sedimentation velocity analyses revealed that it comprised only a simple, sharp peak having a molecular weight of about $6.6 \times 10^{6}$. When treated with $0.4 \mathrm{~N} \mathrm{NaOH}$, about $30 \%$ of the salt-soluble component was precipitated with $50 \%$ ethanol and identified as mucin. From these results, the salt-soluble component of mucosubstance was found to be a mucin complex which presumably exists in the gel structure of egg mass.
\end{abstract}

Key words: mucin, nidamental gland, squid, salt-soluble component

Nidamental gland mucosubstance of squid is responsible for the formation of jelly-like egg masses after spawning, ${ }^{1,2)}$ but little information is available on its chemical properties. Recently, we first reported the occurrence of mucin-type glycoprotein in the mucosubstance from the squid Illex argentinus, ${ }^{3)}$ which is considered to be closely related to the gel structure of egg mass. The mucin was successfully isolated by a mild alkaline treatment $(0.4 \mathrm{~N}$ $\mathrm{NaOH}, 4^{\circ} \mathrm{C}, 4 \mathrm{~h}$ ), followed by precipitation with $50 \%$ ethanol and it accounted for about $35 \%$ of the total mucosubstance. This squid mucin comprised $22.6 \%$ protein, $73.0 \%$ carbohydrate, and $4.4 \%$ ester sulfate and was characterized by its extremely high content of Thr-GalNAc linkage.

Although the mucosubstance contains mucin as a major protein, it is a complex mixture of many proteins. In order to further elucidate its property, the present paper deals with the fractionation of mucosubstance on the basis of solubility. It could be separated into water-soluble, saltsoluble, and insoluble fractions. Particularly, the salt-soluble fraction was featured by a high viscosity and thus analyzed with respect to chemical composition and macromolecular properties. It turned out that the salt-soluble component of mucosubstance is a mucin complex having a huge molecular weight.

\section{Materials and Methods}

\section{Preparation of Nidamental Gland Mucosubstance}

Frozen samples of the nidamental glands of mature squid Illex argentinus were collected at a fish market in Shiogama, Miyagi Prefecture, and stored at $-30^{\circ} \mathrm{C}$ until use. Each sample weighed about $30 \mathrm{~g}$ on average. After thawing in air, the thin membrane of nidamental glands was removed with scissors to obtain the mucosubstance.

\section{Fractionation of the Mucosubstane}

The mucosubstance, $3 \mathrm{~g}$, was homogeneized with $150 \mathrm{ml}$ of deionized water. A water-soluble component was extracted from the homogenates for $18 \mathrm{~h}$ at $4^{\circ} \mathrm{C}$ while gently stirring and was obtained as the supernatant after centrifugation at $95,000 \times g$ for $40 \mathrm{~min}$. Then, the precipitates were homogenized with $150 \mathrm{ml}$ of $0.6 \mathrm{M} \mathrm{NaCl}$ containing $0.02 \mathrm{M}$ sodium phosphate, $\mathrm{pH} 7.2$, followed by incubation for $18 \mathrm{~h}$ at $4^{\circ} \mathrm{C}$ under good stirring. The resulting viscous solution was clarified by centrifugation as described above and treated with $50 \%$ ethanol in order to precipitate the salt-soluble component. The fibrous precipitate thus obtained was washed completely with $60 \%$ ethanol containing $0.1 \mathrm{M} \mathrm{NaCl}$ and dissolved in $0.6 \mathrm{M} \mathrm{NaCl}, \mathrm{pH} 7.2$.

\section{Preparation of Mucin from the Salt-soluble Component}

Mucin was prepared as described previously. ${ }^{3)}$ The saltsoluble component, $200 \mathrm{mg}$, was treated with $100 \mathrm{ml}$ of $0.4 \mathrm{~N} \mathrm{NaOH}$ containing $0.1 \mathrm{M} \mathrm{NaBH}_{4}$ for $4 \mathrm{~h}$ at $4^{\circ} \mathrm{C}$, followed by precipitation with $50 \%$ ethanol containing $0.2 \mathrm{M}$ $\mathrm{NaCl}$. The resulting precipitate, mucin, was collected by low-speed centrifugation and washed with $60 \%$ ethanol containing $0.1 \mathrm{M} \mathrm{NaCl}$. This precipitate was dissolved in water, dialyzed against large volumes of water, and then lyophilized.

\section{Analytical Methods}

Amino acid and amino sugar compositions were determined with an amino acid analyzer (Tosoh HPLC system) after hydrolyses of samples in $6 \mathrm{~N} \mathrm{HCl}$ at $110^{\circ} \mathrm{C}$ for $24 \mathrm{~h}$ and in $4 \mathrm{~N} \mathrm{HCl}$ at $100^{\circ} \mathrm{C}$ for $8 \mathrm{~h}$, respectively. Tryptophan was analyzed after alkaline hydrolysis in the presence of 
$4 \%$ thiodiglycol. ${ }^{4)}$ Neutral sugar composition was determined with a gas chromatograph (Shimazu GC-4C) as trifluoroacetyl derivatives of alditols after hydrolysis in $2.5 \mathrm{~N}$ trifluoroacetic acid at $100^{\circ} \mathrm{C}$ for $7 \mathrm{~h}^{5}$; arabinose was used as an internal standard. Ester sulfate was analyzed by the sodium rhodizonate method. ${ }^{6}$ )

Sedimentation velocity patterns were obtained with an analytical centrifuge (Hitachi model 282) at 55,000 rpm and at $25^{\circ} \mathrm{C}$. Samples were dissolved in $0.6 \mathrm{M} \mathrm{NaCl}$ con-

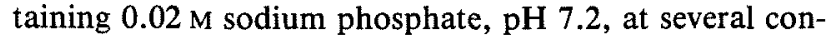
centrations between $0.036 \%$ and $0.076 \%$. The value of sedimentation coefficient was calculated using a partial specific volume of $0.70 \mathrm{~m} / / \mathrm{g}$. Viscosity was measured on $5 \mathrm{~m} l$ sample solution with a Cannon-Fenske viscometer having an average shear gradient of about 1,000 $\mathrm{sec}^{-1}$. SDS-polyacrylamide gel electrophoresis (PAGE) was carried out on $3.5 \%$ gels containing $0.1 \%$ SDS and $3.5 \mathrm{M}$ urea. Protein bands were visualized with Coomassie Brilliant Blue R-250 and molecular weight markers (Sigma) for SDS-PAGE were used as standard proteins.

\section{Results and Discussion}

\section{Preparation of Soluble Components from the Mucosub-} stance

The mucosubstance of nidamental glands was composed of water-soluble, salt-soluble, and insoluble fractions in a weight ratio of $20: 24: 56$. This ratio, however, was variable and depended on the conditions of extraction as well as the maturity of nidamental glands. Both soluble fractions were partially characterized with respect to their chemical compositions and electrophoretic properties. The salt-soluble component in $0.6 \mathrm{M} \mathrm{NaCl}$ was found to give a highly viscous solution and to precipitate as fibrous mass by the addition of $50 \%$ ethanol, while the water-soluble one gave no viscous solution and was not precipitated with $50 \%$ ethanol. Chemical analyses showed that the salt-soluble component was similar in composition to the whole mucosubstance, but not to the water-soluble one. The amino acid, neutral sugar, and amino sugar compositions are listed in Table 1, in terms of residues per 1,000 total residues. The salt-soluble component was relatively rich in threonine, fucose, galactose, and $N$-acetylgalactosamine as well as compound $\mathrm{X}$ which was reported in our previous paper ${ }^{3)}$ as an unidentified amino sugar. On the other hand, the water-soluble component was rich in 2-aminoethanesulfonic acid, taurine, and was very poor in amino sugars, indicating the abundance of nonprotein nitrogen and the virtual absence of mucin, respectively.

When examined by SDS-PAGE, both soluble components were observed to have several protein bands, but were apparently different in their electrophoretic patterns from each other (Fig. 1). The salt-soluble component was uuique in having a protein band which remained at the gel top. This band largely disappeared by the reduction of disulfide bonds with dithiothreitol to give some new bands. The band pattern of the water-soluble component, however, did not change significantly before and after reduction with dithiothreitol.

Macromolecular Properties of the Salt-soluble Component
Table 1. Amino acid and carbohydrate compositions of squid nidamental gland mucosubstance and its soluble components (residues / 1,000 total residues)

\begin{tabular}{|c|c|c|c|c|}
\hline & \multirow{2}{*}{ Mucosubstance $^{* 1}$} & \multirow{2}{*}{$\begin{array}{l}\text { Water-soluble } \\
\text { component }\end{array}$} & \multicolumn{2}{|c|}{ Salt-soluble component } \\
\hline & & & Whole & Mucin \\
\hline \multicolumn{5}{|l|}{ Amino acid } \\
\hline Tau & 26 & 173 & 0 & 0 \\
\hline Asp & 65 & 55 & 64 & 16 \\
\hline Thr & 74 & 37 & 82 & 112 \\
\hline Ser & 28 & 36 & 28 & 4 \\
\hline Glu & 54 & 68 & 47 & 12 \\
\hline Pro & 57 & 53 & 54 & 58 \\
\hline Gly & 51 & 54 & 44 & 14 \\
\hline Ala & 34 & 55 & 29 & 7 \\
\hline Gys/2 & 23 & 7 & 26 & 0 \\
\hline Val & 36 & 31 & 34 & 13 \\
\hline Met & 8 & 10 & 8 & 2 \\
\hline Ile & 48 & 25 & 54 & 56 \\
\hline Leu & 35 & 37 & 34 & 10 \\
\hline Tyr & 21 & 16 & 21 & 5 \\
\hline Phe & 21 & 16 & 20 & 7 \\
\hline Trp & 3 & 1 & 2 & 0 \\
\hline Lys & 51 & 42 & 50 & 15 \\
\hline His & 14 & 12 & 9 & 3 \\
\hline Arg & 22 & 22 & 20 & 7 \\
\hline Total & 671 & 750 & 626 & 341 \\
\hline \multicolumn{5}{|c|}{ Neutral sugar } \\
\hline Rha & 24 & 7 & 21 & 41 \\
\hline Fuc & 59 & 46 & 62 & 91 \\
\hline Rib & 13 & 42 & 14 & 35 \\
\hline Xyl & 24 & 12 & 28 & 46 \\
\hline Man & 19 & 53 & 14 & 8 \\
\hline Glc & 20 & 52 & 12 & 31 \\
\hline Gal & 72 & 21 & 91 & 168 \\
\hline Total & 231 & 233 & 242 & 420 \\
\hline \multicolumn{5}{|l|}{ Amino sugar } \\
\hline GlcNAc & 19 & 10 & 20 & 36 \\
\hline$X^{* 2}$ & 36 & 3 & 53 & 80 \\
\hline GalNAc & 43 & 4 & 59 & 123 \\
\hline Total & 98 & 17 & 132 & 239 \\
\hline Total & 1000 & 1000 & 1000 & 1000 \\
\hline
\end{tabular}

$*_{1}$ Reference 3.

*2 An unidentified amino sugar was determined as a glucosamine equivalnt (Reference 3).

In the solvent of $0.6 \mathrm{M} \mathrm{NaCl}, \mathrm{pH} 7.2$, the molecular shape and weight of the salt-soluble component were estimated by both sedimentation velocity analysis and viscometry. As given in Fig. 2, the homogeneity of the salt-soluble component is evident; a single, sharp peak having a sedimentation constant of $27.7 \mathrm{~S}$ is detected by ultracentrifugal analysis. Moreover, it has a high intrinsic viscosity of $10.0 \mathrm{~d} l / \mathrm{g}$ at $25^{\circ} \mathrm{C}$ (Fig. 3), indicating that the axial ratio of salt-soluble component in solution as a prolate ellipsoid of evolution was about 180 from the equation of Simha." This high viscosity remained almost constant after heat treatment $\left(100^{\circ} \mathrm{C}, 10 \mathrm{~min}\right)$. From these results, the molecular weight was calculated to be about $6.6 \times 10^{6}$ using the Scheraga-Mandelkern equation ${ }^{8)}$ with a value of $3.40 \times 10^{6}$ for $\beta$.

Then, we tried to isolate a mucin from the salt-soluble component by treatment with $0.4 \mathrm{~N} \mathrm{NaOH}$, followed by precipitation with $50 \%$ ethanol. The fibrous precipitate thus obtained was found to be a water-soluble sulfated 


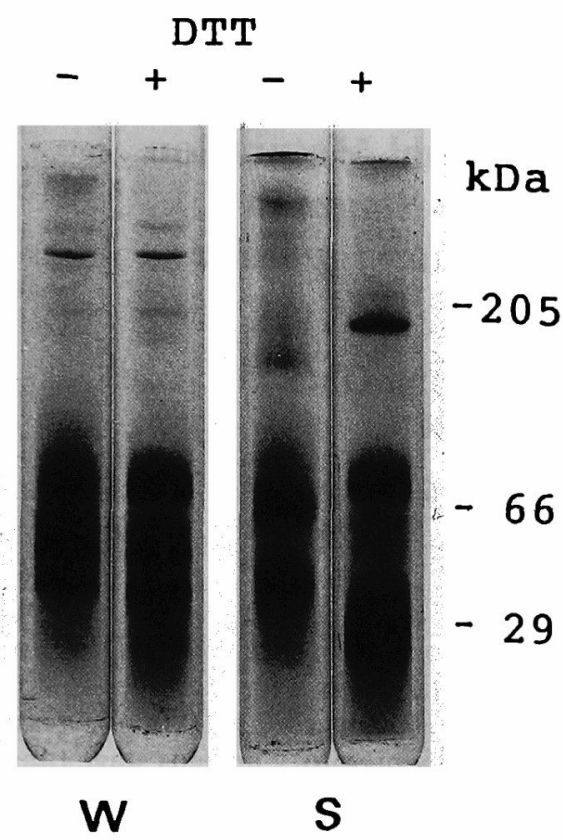

Fig. 1. SDS-polyacrylamide gel electrophoresis of the soluble components from squid nidamental gland mucosubstance.

Each gel was visualized with Coomassie Brilliant Blue R-250. W, water-soluble component; S, salt-soluble component; DTT, dithiothreitol.

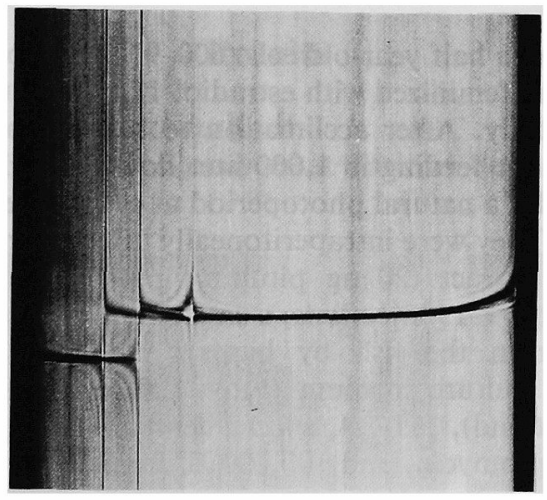

Fig. 2. Sedimentation velocity pattern of the salt-soluble component of squid nidamental gland mucosubstance at $25^{\circ} \mathrm{C}$.

The sample was dissolved in $0.6 \mathrm{M} \mathrm{NaCl}-0.02 \mathrm{M}$ sodium phosphate, $\mathrm{pH} 7.2$, at a concentration of $0.05 \%$. The photograph was taken at $17 \mathrm{~min}$ after the speed of $55,000 \mathrm{rpm}$ was reached.

glycoprotein, mucin, comprising $22.6 \%$ protein, $73.1 \%$ carbohydrate, and $4.3 \%$ ester sulfate by weight. The yield was about $30 \%$ of the salt-soluble component. As shown in Table 1, the mucin is characterized by high !evels of threonine, proline, isoleucine, fucose, galactose, $N$-acetylgalactosamine, and compound $\mathrm{X}$. Furthermore, it has a high intrinsic viscosity of $9.0 \mathrm{~d} l / \mathrm{g}$ in the solvent of $0.6 \mathrm{M}$ $\mathrm{NaCl}$, pH 7.2, (Fig. 3) and could not penetrate a $3.5 \%$ gel when examined by SDS-PAGE (data not shown). These chemical properties are almost identical to those of mucin from the whole mucosubstance as reported previously. ${ }^{3)}$

These composite results have clearly shown that the saltsoluble component of mucosubstance from mature squid is a mucin complex; mucin is associated with other con-

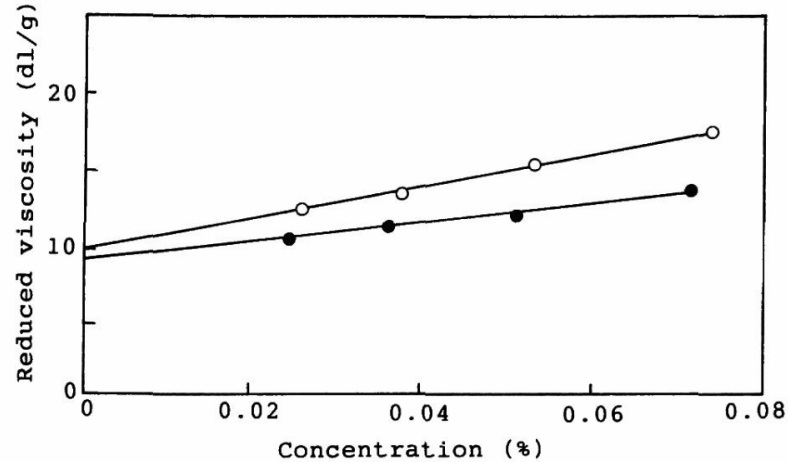

Fig. 3. Intrinsic viscosity of the salt-soluble component of squid nidamental gland mucosubstance at $25^{\circ} \mathrm{C}$ in the solvent of $0.6 \mathrm{M}$ $\mathrm{NaCl}$ containing $0.02 \mathrm{M}$ sodium phosphate, $\mathrm{pH} 7.2$.

$\bigcirc-\bigcirc$ : salt-soluble component, $\bullet-\bullet$ : mucin from the salt-soluble component.

stituents, such as several proteins detected by SDS-PAGE (Fig. 1), to form the salt-soluble component with the high intrinsic viscosity of $10.0 \mathrm{~d} / / \mathrm{g}$ and the huge molecular weight of $6.6 \times 10^{6}$. The salt-soluble component from immature squid, however, was observed to have a larger molecular weight (data not shown), indicating that the degree of association between mucin and other proteins was variable according to the maturity of nidamemtal glands. This mucin complex presumably exists in the egg mass gels. We assume that further aggregation of mucin with other constituents results in the formation of insoluble components. In fact, a preliminary experiment confirmed our assumption that a considerable amount of mucin exists in the insoluble fraction of mucosubstance. The detailed structure of nidamental gland mucin and its complexes remains to be clarified.

Acknowledgments The authors thank Dr. H. Mizuno, Tokyo University of Fisheries, for his help in performing sedimentation analysis and Kibun Foods Inc. for a sample of squid nidamental glands.

\section{References}

1) R. D. Durward, E. Vessey, R. K. O'Dor, and T. Amaratunga: Reproduction in the squid, Illex illecebrosus: First observation in captivity and implications for the life cycle. ICNAF Sel. Papers, 6, 7-13 (1980).

2) M. Okiyama and S. Kasahara: Identification of the so-called "common squid eggs" collected in the Japan Sea and adjacent waters. Bull. Jap. Reg. Fish. Res. Lab., 26, 35-40 (1975).

3) S. Kimura, Y. Sugiura, H. Mizuno, N. Kato, and Y. Hanaoka: Occurrence of a mucin-type glycoprotein in nidamental gland mucosubstance from the squid Illex argentinus. Fisheries Sci., 60, 193-197 (1994).

4) F. J. Oelshlegel, Jr., J. R. Schroeder, and M. A. Stahmann: Simple procedure for basic hydrolysis of proteins and rapid determination of tryptophan using a starch column. Anal. Biochem., 34, 331-337 (1970).

5) T. Imanari, Y. Arakawa, and Z. Tamura: Gas chromatographic analysis of aldoses. Chem. Pharm. Bull., 17, 1967-1969 (1969).

6) T. T. Terho and K. Hartiala: Method for determination of the sulfate content of glycosaminoglycans. Anal. Biochem., 41, 471 -476 (1971).

7) R. Simha: The influence of Brownian movement on the viscosity of solutions. J. Phys. Chem., 44, 25-34 (1940).

8) H. A. Scheraga and L. Mandelkern: Consideration of the hydrodynamic properties of proteins. J. Amer. Chem. Soc., 75, 179-184 (1953). 